\title{
O PIBID E A FORMAÇÃO DE PROFESSORES: DA MAGNITUDE DO PROGRAMA AOS DESAFIOS FORMATIVOS INSTITUCIONAIS
}

\author{
THE PIBID AND TEACHER TRAINING: \\ THE MAGNITUDE OF THE PROGRAM TO INSTITUTIONAL TRAINING CHALLENGES \\ O PIBID E A LA FORMACIÓN DE PROFESORES: \\ DA MAGNITUD DEL PROGRAMA A LOS DESAFÍOS FORMATIVOS INSTITUCIONALES

\section{Claudia Gomes ${ }^{1}$ \\ Helena Maria dos Santos Felício ${ }^{2}$} \\ RESUMO: Este estudo tem como objetivo problematizar os propósitos e os desafios formativos postos para a \\ formação docente anunciados pelos projetos institucionais do Programa Institucional de Bolsas de Iniciação à \\ Docência (PIBID) nas Instituições de Ensino Superior (IES) no território mineiro. Embasado em um \\ delineamento documental foram analisados objetivos institucionais de 39 projetos desenvolvidos entre os anos \\ de 2009 e 2014. Como resultado evidenciou-se que as premissas sustentadoras dos projetos nas IES defendem \\ como pressupostos o alinhamento do programa as ações de valorização e qualificação do trabalho docente, \\ assim como na compreensão da relação Universidade/escola e a interface na/da formação/atuação docente.
}

PALAVRAS-ChAVE: Formação docente. Licenciatura. Programa Institucional de Bolsas de Iniciação à Docência

ABSTRACT: This study aims to discuss the purposes and post training challenges for teacher training announced by institutional projects of the Institutional Scholarship Program Introduction to Teaching (PIBID) in univesrsities in the Minas Gerais territory. Grounded in a documentary design were analyzed institutional aims of 39 projects developed between 2009 and 2014. As a result it became clear that the assumptions supportive of projects defend as assumptions the program align the stock valuation and qualification of teaching as well as in understanding the relationship University / school and the interface in the / training / teaching performance.

KEYWORDS: Teacher education. Degree. Scholarship Program of Introduction to Teaching.

RESUMÉN: Este estudio tiene como objetivo problematizar los propósitos y los desafíos formativos puestos para la formación docente anunciados por los proyectos institucionales del Programa Institucional de Becas de Iniciación en Docencia (PIBID) en las Instituciones de Educación Superior (IES) en el territorio minero. En el marco de un delineamiento documental se analizaron objetivos institucionales de 39 proyectos desarrollados entre los años 2009 y 2014. Como resultado se evidenció que las premisas sustentadoras de los proyectos en las IES defienden como presupuestos la alineación del programa las acciones de valorización y calificación del trabajo docente, así como en la comprensión de la relación Universidad/escuela y la interfaz en la/de la formación/actualización docente.

PAlABRAS ClAVE: Formación docente. Licenciatura. Programa Institucional de Becas de Iniciación en Docencia.

Submetido em:23/10/2017 - Aceito em: 05/11/2017 - Publicado em: 09/11/2017.

\begin{tabular}{l|c|c|c|c|c|c|} 
(C) Rev. Educ. Perspec. & Viçosa, $M G$ & v.8 & n.3 & p.426-443 & set./dez. 2017 & eISSN 2178-8359 \\
\hline
\end{tabular}




\section{INTRODUÇÃO}

Este texto, como parte integrante da pesquisa intitulada "Programa Institucional de Bolsa de Iniciação à Docência (PIBID): Caracterização e análise do impacto na formação dos licenciandos em Minas Gerais", financiada pela Fundação de Apoio à Pesquisa do Estado de Minas Gerais (FAPEMIG), tem como objetivo problematizar os propósitos e os desafios formativos posto para a formação docente anunciados pelos projetos institucionais do Programa Institucional de Bolsas de Iniciação à Docência (PIBID) nas Instituições de Ensino Superior (IES) no território mineiro.

Este estudo compreende o período entre 2009 e 2014 por abarcar o início, a expansão e a consolidação do PIBID em território nacional por intermédio de vários editais lançados pela Coordenação de Aperfeiçoamento de Pessoal de Nível Superior (CAPES), responsável pela sua implementação.

Nas últimas décadas, a centralidade do professor no trabalho educacional institucionalizado, bem como sua formação inicial e continuada, tem assumido considerável destaque nos discursos políticos e científicos, sobretudo em função da relação direta que se estabelece entre a qualidade da educação - expressa, geralmente, em avaliações do sistema educacional - e a competência profissional do professor. Ou seja, de acordo com tais discursos, um processo educacional de qualidade depende, não só, mas fundamentalmente de um docente que tenha uma sólida formação profissional.

De acordo com Gatti (2010), não há dúvidas que a formação dos professores ainda é um desafio para as políticas governamentais, assim como para as instituições formadoras, e que um dos cernes desta problematização é o avanço para perspectivas formativas baseadas na compreensão social, cultural e econômica da profissão docente; a definição do perfil profissional docente; a compreensão dos desafios curriculares e programáticos no processo de formação; até por fim, a ausência de uma carreira atrativa e com condições favoráveis de trabalho.

Dentre os desafios curriculares e programáticos no percurso da formação inicial, a relação entre teoria e prática se apresenta como um elemento dilemático, que ainda precisa ser (re)estruturado de modo que a mesma se torne, efetivamente, como parte de tal processo.

Segundo Flores (2000, p. 155), a relação entre teoria e prática deve ser entendida como "unidade indissolúvel", que supera a organização curricular hierarquizada, onde a formação geral antecede a formação específica, excluindo a visão de que há um momento certo para cada uma delas. No entanto, como este processo relacional se apresenta como uma realidade

\begin{tabular}{l|c|c|c|c|c|c} 
() Rev. Educ. Perspec. & Viçosa, $M G$ & v.8 & n.3 & p.426-443 & set./dez. 2017 & eISSN 2178-8359 \\
\hline
\end{tabular}


difícil de ser alcançada, sobretudo pela academização sob a qual se estruturou a formação de professores nas IES (FORMOSINHO, 2009), temos assistido a várias iniciativas governamentais em prol da formação inicial de professores, destinadas a "fortalecer os vínculos entre as instituições formadoras e o sistema educacional, suas escolas e seus professores" (BRASIL, 2002, p. 5). Dentre essas iniciativas, o PIBID tem assumido um destaque no cenário nacional, principalmente pela sua magnitude que tem impactado, de forma significativa, os cursos de formação inicial de professores.

Em termos de política pública destinada ao aperfeiçoamento e a valorização da formação inicial de professores para a Educação Básica, o PIBID, criado pelo decreto $\mathrm{n}^{\mathbf{0}} 7.219$ $\left(\right.$ BRASIL, 2010) ${ }^{\mathrm{i}}$ sob a responsabilidade da CAPES, se instaura com o objetivo de elevar a qualidade da formação inicial de professores nos cursos de licenciatura, promovendo a integração entre Ensino Superior e Educação Básica, a partir da inserção dos licenciandos no cotidiano de escolas da rede pública de educação, proporcionando-lhes oportunidades de criação e participação na prática docente. Desde então as IES interessadas em participar do PIBID apresentam à CAPES seus projetos institucionais de iniciação à docência conforme publicação dos editais.

Como afirmamos em trabalho anterior,

\begin{abstract}
o Programa consiste em uma iniciativa que contribui diretamente para a superação da questão da relação teoria-prática / espaço de formação-espaço de atuação na formação docente, na medida em que permite passarmos do discurso de um "novo" modelo de formação, no qual se prevê que esta relação ocorra de modo dialético e retroalimentador, tomando-o como uma diretriz para o desenvolvimento de uma formação de melhor qualidade, diretamente implicada "no" e "com" o espaço de atuação profissional (GOMES, SANTOS; FELÍCIO, 2014, p. 16).
\end{abstract}

O que se pode observar é que, mesmo recente, o programa já atrai o interesse de pesquisadores e especialistas da área. Um levantamento realizado com as primeiras pesquisas publicadas aponta 12 estudos que problematizam desde seus os princípios políticos, até os desafios e perspectivas operacionais do programa no cotidiano das escolas parceiras.

Estes estudos se caracterizam como relatos de experiências das ações desenvolvidas no programa, bem como enfatizam o debate em diferentes segmentos de ensino (educação infantil, ensino fundamental e ensino superior), enfocando desde as ações do programa e seus benefícios às escolas públicas, no que concerne o desenvolvimento de metodologias, práticas de ensino, discussões teóricas acerca da realidade escolar, até o impacto das ações do programa para a configuração da identidade docente como mecanismo de valorização da profissão. (OLIVEIRA, LUGLE, 2013; JARDILINI. OLIVERI, 2013; FERNANDES, MENDONÇA, 2013; DRIEDRICH, CAIMI, BRAGAGNOLO, 2013; SOUZA; NASCIMENTO, 2009).

\begin{tabular}{l|c|c|c|c|c|c|} 
(C) Rev. Educ. Perspec. & Viçosa, $M G$ & v.8 & n.3 & p.426-443 & set./dez. 2017 & eISSN 2178-8359 \\
\hline
\end{tabular}


Estas ações, propostas pelo PIBID, têm proporcionado à escola pública assumir-se enquanto protagonista no processo de formação inicial de professores, sobretudo pelo reconhecimento do potencial que os professores mais experientes têm para atuar como coformadores desses futuros docentes (NÓVOA, 2012).

Este é um dos aspectos essenciais que tem fortalecido o PIBID e sustentado o seu crescimento vertiginoso em todo território nacional no período entre 2009-2014. Entretanto, a partir do edital 61/2013 o programa passa por reestruturações, dando início a um novo ciclo de sua existência, mas, conservando sua essência conforme os objetivos elucidados anteriormente.

Para tanto, considerando que o primeiro ciclo do PIBID, que vai do decreto de criação ao edital de 2013, este estudo lança como objetivo problematizar os propósitos anunciados pelos projetos institucionais do referido programa, traçados pela magnitude do programa nas Instituições de Ensino Superior (IES) no território mineiro, e os desafios formativos institucionais postos para a formação docente.

\section{PIBID: DA MAGNITUDE DO PROGRAMA EM MINAS GERAIS}

O PIBID em Minas Gerais assumiu uma proporção bastante expressiva. Constatou-se que o Programa é desenvolvido por 39 IES, cada uma desenvolvendo 01 Projeto Institucional que integra vários subprojetos de acordo com as licenciaturas oferecidas por tais instituições. Entretanto, percebeu-se um movimento crescente do PIBID, a partir dos diferentes editais, uma vez que era possível às IES fazer inserções de novos projetos institucionais e/ou ampliações daqueles existentes.

O expressivo número de subprojetos desenvolvidos, como indica a tabela 1 , deve-se ao envolvimento dos diversos cursos de licenciaturas existentes nas IES que, ao assumirem a importância deste Programa na formação inicial de professores, especialmente pela valorização da mesma mediante a concessão de bolsa aos graduandos, integram professores e licenciandos no desenvolvimento de atividades em escolas públicas. 
Tabela 1: Crescimento do PIBID em Minas Gerais

\begin{tabular}{cccc}
\hline Edital & IES & Projetos Institucionais & Subprojetos \\
\hline $\mathbf{2 0 0 9}$ & 13 & 13 & 111 \\
$\mathbf{2 0 1 1}$ & 15 & 28 & 263 \\
$\mathbf{2 0 1 2}$ & 20 & 33 & 281 \\
$\mathbf{2 0 1 3}$ & 39 & 39 & 302 \\
\hline
\end{tabular}

Fonte: As autoras

Os subprojetos que incorporam o Projeto Institucional do PIBID em cada IES são estruturados a partir dos cursos de licenciaturas que as mesmas oferecem. Desta forma, o gráfico 1 demonstra que a distribuição dos subprojetos, pelas áreas das licenciaturas em todo estado de Minas Gerais, não se dá de forma homogênea, sobretudo em função da natureza dos cursos, número de oferta e de alunos.

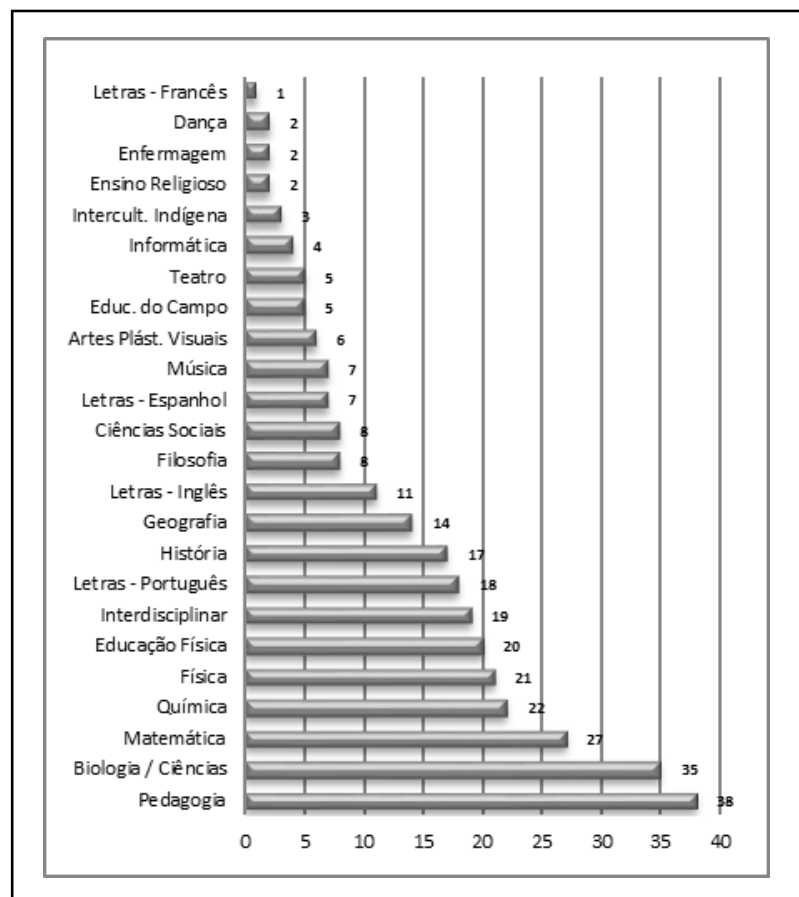

Gráfico 1: Áreas das Licenciaturas que abrigam subprojetos do PIBIB em Minas Gerais. Fonte: As autoras

É possível constatar que as áreas são bem definidas, de acordo com os cursos de licenciaturas oferecidos pelas IES, preservando a maior concentração nas licenciaturas mais "tradicionais", onde a similaridade entre essas áreas e as disciplinas da educação básica são respeitadas. Entretanto, percebemos a existência de subprojetos que extrapolam esta lógica, como exemplo: subprojetos interdisciplinares (19) que articulam duas ou mais áreas de conhecimento; educação do campo (5); teatro (5); intercultural indígena (3); enfermagem (2); 
dança (2); que, em uma concepção ampliada de educação e de currículo, oferecem contribuições significativas à formação inicial de professores e ao contexto escolar, sobretudo por agregar conhecimentos e habilidades pouco trabalhadas em ambas as situações.

No que se refere ao elemento humano, o PIBID envolve quatro níveis de participação: professores coordenadores dos programas nas IES (coordenador institucional e coordenador de gestão), professores das licenciaturas nas IES (coordenadores de área), professores das escolas de educação básica (supervisores) e os licenciandos, que são considerados os sujeitos centrais do Programa, uma vez que sua existência está diretamente articulada com a melhoria do processo de formação inicial deste profissional.

Quando a organização nacional do programa institui funções como coordenadores institucionais, de gestão e de área ${ }^{\mathrm{ii}}$, com atribuições diferenciadas que vão desde o gerenciamento técnico-burocrático do programa até o desenvolvimento didático-pedagógico das ações do programa nas escolas parceiras, favorece que um considerável contingente de profissionais das IES se envolva no trabalho com a formação inicial de professores, especialmente no estreitamento de relações entre a universidade e as escolas de educação básica, como podemos verificar no gráfico 2 .

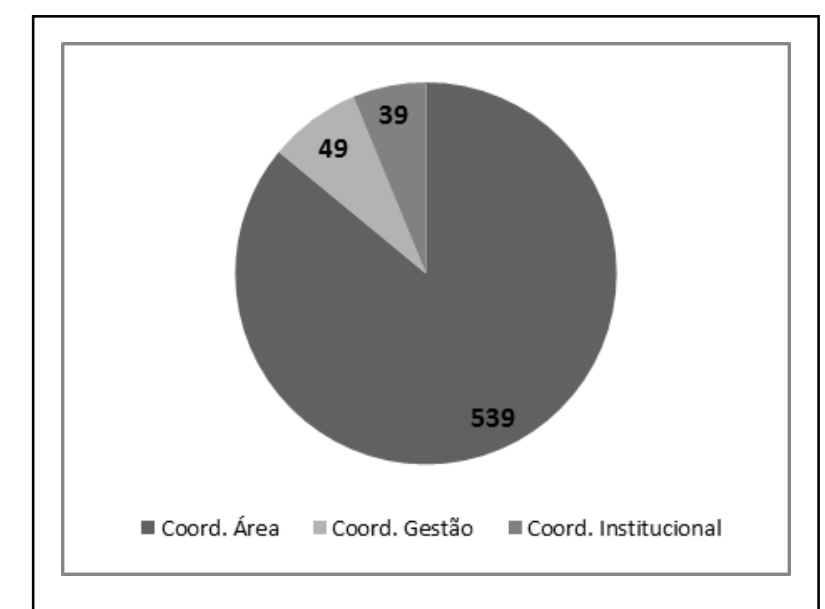

Gráfico 2: Profissionais das IES mineiras envolvidos no PIBID.

Fonte: As autoras

Podemos considerar que este envolvimento de diversos professores no programa é um fator positivo, sobretudo porque contribui com a dissolução de concepções cristalizadas, em muitas instituições, que destinam somente aos profissionais da "área pedagógica" a responsabilidade do trabalho com a formação de professores e a iniciação à prática docente, como se o conhecimento específico não tivesse nenhuma participação neste tipo de formação profissional. 
Desta forma, de acordo com a Portaria no 96/2013, a CAPES estabelece, no artigo 35, que estes professores devem possuir formação na área do subprojeto, bem como, experiência comprovada na formação de professores em pelo menos dois dos seguintes critérios: "a) orientação de estágio em curso de licenciatura; b) curso de formação ministrado para professores da educação básica; c) coordenação de programas ou projetos de formação para o magistério na educação básica; d) experiência como docente ou na gestão pedagógica da educação básica; e) produção na área".

Assim, esses professores, particularmente de áreas específicas, que das mais diversas áreas das licenciaturas, se integram ao PIBID, corroboram para que a compreensão sobre a formação de professores seja alargada e envolvente, no sentido de corresponsabilizar todos os profissionais envolvidos nos cursos de licenciaturas pela formação inicial de professores, tanto no seu aspecto específico quanto didático-pedagógico.

Nesta perspectiva, o programa contribui para que, na formação deste profissional, seja superado "o individualismo imperante na prática de formação de professores, que se centra mais na aquisição individual de conteúdos" (ALONSO; SILVA, 2005, p. 57), em prol de um processo de construção coletiva, onde o conhecimento profissional seja partilhado, enquanto uma exigência ética da própria função docente.

Entretanto, concordamos que este processo de construção coletiva se constitui enquanto um desafio que marca todo o percurso histórico da formação. Ou seja, mesmo após a emancipação da licenciatura e da abolição do modelo " $3+1$ " ao se desvincular do bacharelado, é perceptível que ainda há a segregação das disciplinas pedagógicas e de conhecimento específico dentro dos cursos de licenciatura. Percebe-se, ainda, que as disciplinas pedagógicas e, consequentemente seus professores, sofrem uma discriminação em relação às disciplinas de conhecimento específico, provocando a falta de articulação que compromete a formação e o exercício da profissão em diversos níveis (GOMES, BAZON, LOZANO, no prelo).

Nesta mesma linha de raciocínio, a construção coletiva da profissão professor, no contexto do PIBID, ultrapassa os limites das IES, quando considera a escola pública e a prática profissional como instituições formadoras, mediante a inclusão de professores da educação básica que, ao assumir-se como supervisor dos licenciandos no contexto de trabalho, passam a ser considerados como coformadores destes futuros professores.

Desta forma, reconhecer a dimensão formativa dos contextos educacionais supõe compreender que a

Prática profissional constitui um lugar original de formação e de produção de

saberes, pois ela é portadora de condições e de condicionantes específicos que não

\begin{tabular}{l|c|c|c|c|c|c|} 
(C) Rev. Educ. Perspec. & Viçosa, $M G$ & v.8 & n.3 & p.426-443 & set./dez. 2017 & eISSN 2178-8359 \\
\hline
\end{tabular}


se encontram noutra parte nem podem ser reproduzidos "artificialmente", por exemplo, num contexto de formação teórica na universidade ou num laboratório de pesquisa (TARDIF, 2002, p. 288).

Em Minas Gerais, o PIBID mobiliza 1.465 professores da educação básica que, vinculados a um determinado subprojeto de área, como podemos verificar no gráfico 3, exercem uma função em que as atribuições, descritas no artigo 42 do Regulamento do Programa (CAPES, 2013) envolvem: elaboração, desenvolvimento e acompanhamento das atividades dos licenciandos; controle de frequência dos licenciandos na escola; manter o coordenador de área avisado sobre o andamento do subprojeto na escola; informar à comunidade escolar sobre o desenvolvimento do subprojeto; participar das atividades do Programa; fazer relatórios; dentre outras.

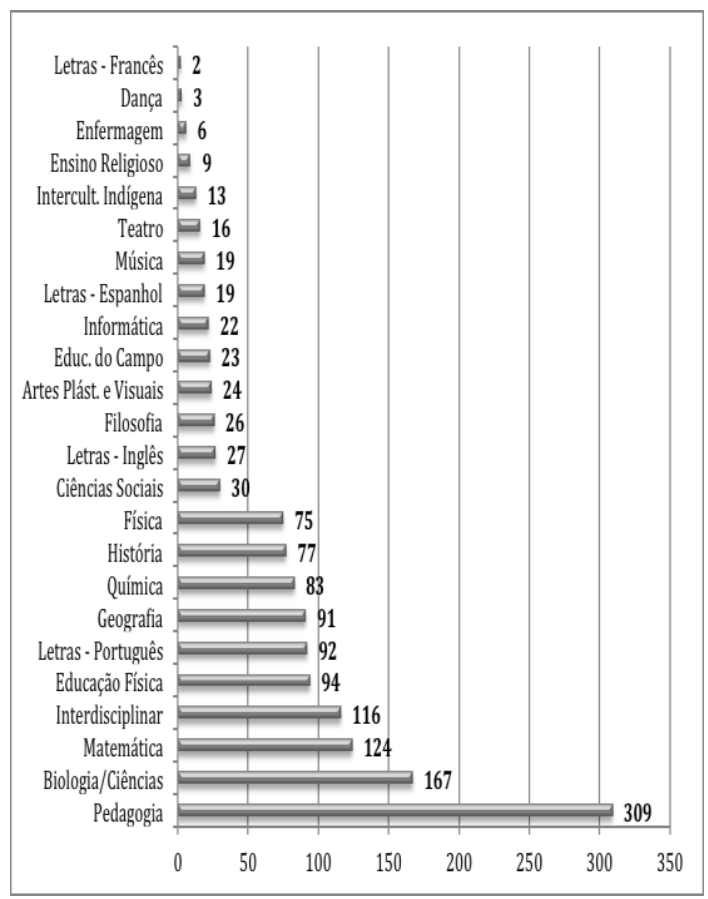

Gráfico 3: Distribuição de supervisores por licenciaturas Fonte: As autoras

No entanto, entendendo a supervisão como o "processo em que um professor, em princípio mais experiente e mais informado, orienta outro professor ou candidato a professor no seu desenvolvimento humano e profissional" (ALARCÃO, TAVARES, 2013, p. 16), reconhecemos o papel central deste supervisor no desenvolvimento do Programa, pois ele integra os licenciandos ao contexto escolar, viabiliza, orienta e acompanha as atividades dos mesmos nas escolas de educação básica, exercendo um processo de supervisão mais próxima e direta - ação que, muitas vezes, o professor das IES não consegue realizar com tanta propriedade. 
Em Minas Gerais, este número expressivo de professores do ensino superior e da educação básica envolvidos no PIBID, se responsabilizam pela formação de 8.299 licenciandos que participam do programa e se encontram vinculados a um determinado subprojeto.

Ao serem selecionados, esses licenciandos se comprometem com o desenvolvimento das atividades previstas pelos subprojetos nas escolas parceiras. Entretanto, há de se considerar que, ao ser a formação inicial destes licenciandos o foco principal do Programa, tais atividades devem ser estruturadas de modo que contribuam para que esta formação seja garantida de forma consciente e intencional. Ou seja, é necessário assumir esta dimensão formativa do Programa para que o mesmo não seja interpretado, somente como ações que venham contribuir para a melhoria da escola ou para sanar alguma dificuldade que a mesma apresenta.

Na mesma distribuição dos subprojetos e dos supervisores, o gráfico 4 apresenta como os licenciandos estão ordenados nas diferentes áreas das licenciaturas.

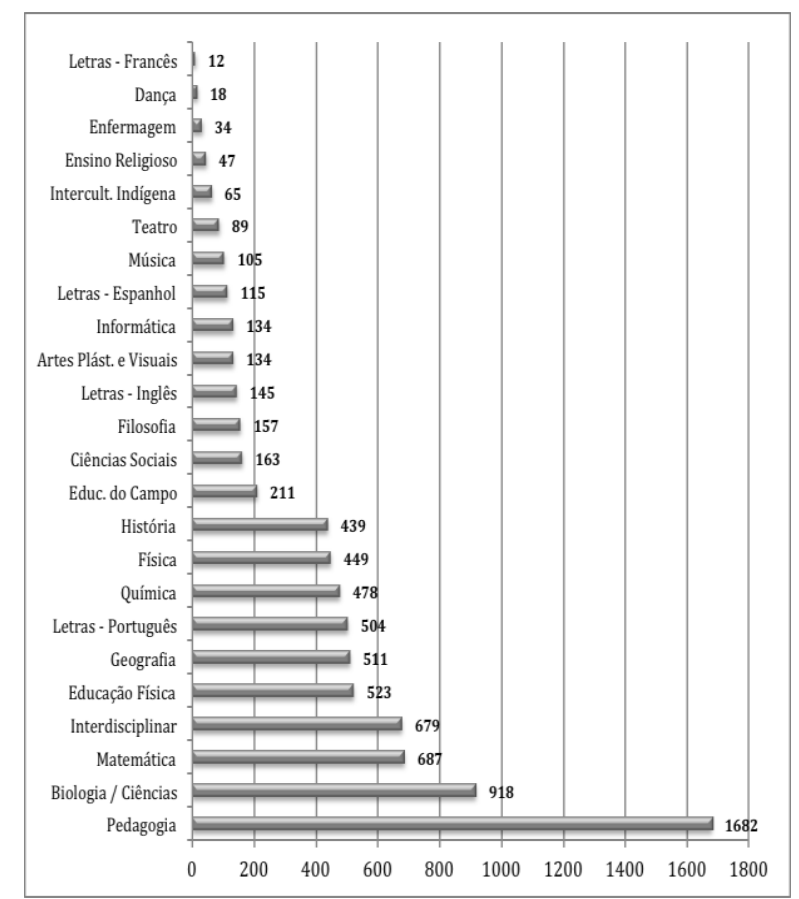

Gráfico 4: Distribuição dos licenciandos por licenciatura Fonte: As autoras

Embora esse número de licenciandos, participantes do PIBID em Minas Gerais pareça expressivo, o Programa não abarca a totalidade de acadêmicos que, cursando a licenciatura, intencionam a docência como profissão. Entretanto, aqueles que participam do programa estão integrados em projetos que intencionam impactar, positivamente, o processo de 
formação inicial destes futuros professores. Sendo assim, passamos a analisar os objetivos destes projetos institucionais.

PIBID: Desafios formativos institucionais

Com base em estudos anteriores (GOMES, FELÍCIO, 2012; FELICIO; GOMES; ALLAIN, 2014) não temos dúvida de que o PIBID favorece um novo e importante espaço para a formação docente inicial, na medida em que as atividades contempladas pelo programa oferecem elementos que favorecem a produção de novos sentidos sobre a docência (GOMES; SOUZA, 2012), como por exemplo: o conhecimento ampliado da realidade escolar e do sistema de ensino como premissa para a ampliação de uma reflexão profissional; o processo contínuo de pensar e repensar a escolha da docência como profissão; a inserção no espaço real de trabalho; entre outros elementos. Entretanto, chamamos a atenção para a efetividade desta ação frente aos desafios formativos institucionais impostos às IES para a formação e profissionalização docente.

Os objetivos institucionais assumidos pelas IES vinculadas ao PIBID, mediante os 39 projetos analisados no período de 2009 a 2014, foram organizados a partir de duas categorias de análise como descrito a seguir:

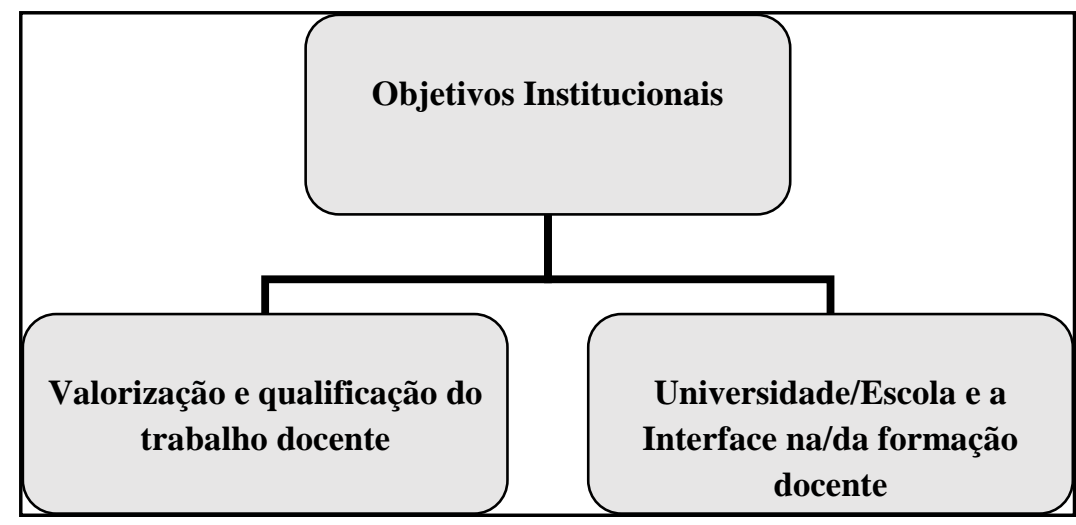

Figura 1: Categorias de análise Fonte: As autoras

\section{Valorização e qualificação do trabalho docente}

O que se evidencia nos objetivos institucionais classificados nesta categoria é que, de modo geral, as instituições compreendem que a vinculação ao programa deve estar alinhada à discussão mais ampla da formação e profissionalização docente.

Objetivos traçados para o debate sobre a formação continuada; qualidade do trabalho docente; elevação da qualidade das ações acadêmicas; valorização do magistério e qualidade da educação básica, são indicados como pressupostos dos projetos institucionais das IES.

\begin{tabular}{l|l|l|l|l|l|l} 
(ㅇ Rev. Educ. Perspec. & Viçosa, $M G$ & v.8 & n.3 & p.426-443 & set./dez. 2017 & eISSN 2178-8359 \\
\hline
\end{tabular}


Entendemos que o alinhamento destes objetivos traçados pelos projetos institucionais tem como base as diretrizes do próprio Programa, que explicitam a necessidade de

\begin{abstract}
Incentivar a formação de docentes em nível superior para a educação básica; contribuir para a valorização do magistério; incentivar escolas públicas de educação básica, mobilizando seus professores como coformadores dos futuros docentes e tornando-as protagonistas nos processos de formação inicial para o magistério; contribuir para a articulação entre teoria e prática necessárias à formação dos docentes, elevando a qualidade das ações acadêmicas nos cursos de licenciatura. (BRASIL, 2010).
\end{abstract}

Consideramos que o traçado de tais objetivos são claros e demarcam a condição de vinculação ao programa. No entanto, adotar tais princípios é alocar a discussão sobre a formação e atuação docente em uma nova esfera de problematização dentro das instituições de ensino superior que se encontra na paralela dos cursos de licenciaturas, pois enfatizam um aspecto prático da formação, com resultados imediatos que devem projetar-se no cotidiano das escolas de educação básica.

Estas problematizações fazem parte das conquistas alcançadas pela formação docente em nível superior. Porém, segundo Oliveira (2010), tais conquistas ocorrem numa época em que há a expansão do ensino público, o que deflagra uma necessidade muito maior pela quantidade de professores do que pela qualidade da formação. Neste sentido, a urgência na formação favorece o apressamento das propostas curriculares, que objetivam uma formação técnica, rápida e de massas (CUNHA, 1999), a fim de responderem ao déficit da quantidade apresentado pelo contexto educacional brasileiro que pressionam, por assim dizer, os cursos de licenciaturas.

Assim nos questionamos se a ânsia de resolução da demanda de formação acadêmica, com base em legislações que se debruçam apenas no fato de elevar o nível de escolaridade dos profissionais, como se fosse suficiente para atender as demandas atuais e inserir estes profissionais no mercado, não se contrapõe a um debate dos reais e atuais desafios da profissão que impactam sobremaneira a formação docente, como por exemplo: condições de trabalho, valorização da carreira, ou mesmo, a existência de planos de acesso entre outros elementos definidores para a escolha da docência como profissão (PAIVA; GOMES, 2014). Assim, enquanto as IES não abordarem efetivamente tais questões em suas ações formativas estarão reforçando uma política que garante uma formação aligeirada com a inserção rápida de profissionais nas escolas, sem o compromisso com a qualidade e o desenvolvimento profissional de seus alunos - futuros docentes, e que com isso perpetua a lógica de que a "falta de formação" é responsabilidade exclusiva do profissional. 
Ainda no que tange os desafios institucionais em relação à valorização e qualificação do trabalho docente e da escola, lançamos como problematização dos espaços formativos a discussão da formação do formador no âmbito da IES.

De acordo com os estudos de Arroio (2006), a universidade vem apresentando dificuldades em formar seu quadro de professores capacitados no ensino, uma vez que para ingressar na carreira acadêmica, o profissional deve ser aprovado em concursos que, de um modo geral, prioriza seu percurso enquanto pesquisador, não garantindo a qualidade profissional, principalmente, em relação à formação pedagógica necessária na atuação docente.

Assim, por mais atrativo que seja um programa de formação que possibilite a revisão aos alunos participantes da destituição do modelo " $3+1$ ", o que vemos é a existência de cursos fragmentados e dispersos com a prevalência dos conteúdos das áreas disciplinares (GATTI; BARRETO, 2009). Destarte, muita atenção é necessária para que não se corra o risco de produzir modelos que resultem da inversão destas equivocadas e históricas lógicas de modelos formativos.

\section{Universidadelescola e a interface na/da formação/atuação docente}

Nesta categoria identificamos que os objetivos assumidos pelas IES no desenvolvimento do programa dizem respeito à inserção e participação dos protagonistas no cotidiano escolar; a bidirecionalidade da relação universidade/escola na formação e atuação docente; o desenvolvimento de ações inovadoras e alternativas metodológicas; a otimização do processo de ensino e aprendizagem; o espaço de experiências metodológicas e as experiências pedagógicas como eixos transversais no processo de formação.

Entendemos que o fato da instituição formativa alinhar seu projeto institucional aos pressupostos do programa só será efetivamente uma ação de transformação para a formação docente se este alinhamento provocar tensões e problematizações nas organizações curriculares e formativas adotadas, caso contrário corre-se o risco de perpetuar uma ação de formação isolada e autônoma, configurando-se um "terceiro espaço" da formação docente, situando tanto a formação docente como a escola como apêndices do processo formativo.

Em estudos anteriores (FELÍCIO; 2014) defendemos o PIBID enquanto "terceiro espaço", na medida em que o mesmo favorece relações mais igualitárias entre as universidades e escolas de modo que o conhecimento sobre a docência possa ser construído por intermédio da relação dialética e compartilhada desses dois espaços formativos. 
Esta questão apresenta desafios tanto às escolas de educação básica no sentido de se assumirem enquanto instituições que carregam em seu cotidiano um potencial formativo, quanto às IES que precisam colocar-se em uma relação de horizontalidade com as primeiras.

Neste sentido, percebemos que o PIBID favorece um novo e importante espaço para a formação docente inicial. No entanto, a dicotomia teoria e prática, assim como a necessidade de espaços para a reflexão sobre a ação, e a falta de clareza do caráter mediador do processo formativo fragilizam o processo de formação, contribuindo para a autonomia dos licenciandos/professores (GOMES, SOUZA, 2012).

Percebemos que a compreensão da aprendizagem da docência, na prática, está intimamente relacionada à demanda atual que demarca que parte das atribuições e qualificações docentes são desenvolvidas pela lógica da compreensão do ato pedagógico como ação pragmática, corolário do "aprender fazendo", "aprender em serviço", "aprender praticando" (ARCE, 2001).

A formação docente quando considerada apenas sob a perspectiva das competências e habilidades necessárias, reflete uma compreensão simplista, que com base na regulamentação, considera que uma vez adquirido o rol de qualificação, o sujeito tem concluída sua formação. Entretanto, essa compreensão reduz o saber docente ao como fazer, com vistas apenas aos procedimentos técnicos, ao manejo e transmissão das informações acadêmicas (CUNHA, 1999).

Entretanto, defendemos que é no agir cotidiano que novas possibilidades de interações podem ser estabelecidas e confirmar a constituição do desenvolvimento humano em sua complexidade, espaço este que materializa o processo de se ensinar a pensar, o que exige a construção e reconstrução do professor crítico e reflexivo de sua prática profissional (GOMES, SOUZA, 2012), no entanto, tais ações dependem de ações mediadoras, que possibilitem a configuração de sentido que ampliem a vivência no programa como um espaço profícuo de "certificação e segurança na escolha profissional".

Para Nóvoa (1997), o que não pode ser silenciado neste contexto é a perspectiva de formação crítico-reflexiva, que dotariam os professores de uma verdadeira formação intelectual, premissa para a articulação de uma prática educacional de fato emancipatória. Assim, a profissionalização do professor precisa estar embasada em uma construção pedagógica não focada na instrumentalização, mas naquela que legitime os professores como produtores de saberes, distantes das dicotomias teoria/prática; conhecimento/ação, entre outras. E que acima de tudo, favoreça um resgate social da profissão docente, com a definição de proposições políticas educacionais coerentes, que propiciem aos docentes redescobrir sua identidade e cumprir o seu papel na formação dos educandos.

\begin{tabular}{l|c|c|c|c|c|c} 
() Rev. Educ. Perspec. & Viçosa, $M G$ & v.8 & n.3 & p.426-443 & set./dez. 2017 & eISSN 2178-8359 \\
\hline
\end{tabular}




\section{CONSIDERAÇÕES FINAIS}

Este estudo teve a finalidade de apresentar a caracterização do PIBID em Minas Gerais, no que diz respeito à sua estruturação e organização, bem como problematizar os propósitos anunciados pelos projetos institucionais nas Instituições de Ensino Superior em território mineiro.

Em relação a adesão das instituições de ensino superior ao programa entre os anos de 2009 até o ano de 2014 foi evidenciado um aumento de 300\%, assim como de $272 \%$ de novos subprojetos distribuídos em diferentes áreas da Licenciatura, ou ainda com o desenvolvimento de temáticas específicas, como por exemplo, projetos interdisciplinares que articulam duas ou mais áreas de conhecimento: educação do campo; teatro; intercultural indígena; enfermagem e dança.

Em relação ao número de participantes de acordo com os dados disponibilizados no final de 2013 o programa contemplava 539 coordenadores de área, 49 coordenadores de gestão e 39 coordenadores institucionais responsáveis pelo encaminhamento pedagógico, técnico e institucional das ações previstas nos projetos institucionais. Já em relação aos supervisores de área - professores das escolas públicas parceiras do programa, a estimativa de participação era de 1.465, assim como 8.299 licenciandos de diferentes áreas e vinculados ao PIBID em Minas Gerais.

Da perspectiva quantitativa não nos resta dúvida do impacto do PIBID nas Instituições de Ensino Superior, assim como nas escolas públicas parceiras, fato este reafirmado com a compreensão do programa como uma política permanente de formação docente sancionada pela Lei de Diretrizes e Bases Nacionais no ano de 2013.

No entanto, para além dos impactos estruturais, de recursos e financiamentos que o PIBID oferta, análises e discussões quanto aos desdobramentos do programa para a formação docente inicial e continuada se tornam de extrema relevância. O primeiro elemento de análise parte do próprio formato oficial do programa que favorece o desenvolvimento de um espaço de formação coletiva e cotidiana ao ofertar uma maior aproximação com as diversas realidades que caracterizam a profissão e a seus protagonistas. Neste sentido, consideramos que o PIBID tem a possibilidade de revisitação da dicotomia histórica que ainda sustenta a formação e profissionalização docente: teoria/prática; preparação para o ensino/preparação para a pesquisa; preparação teórica/preparação prática.

Evidenciamos que com base nos objetivos institucionais um dos eixos norteadores das ações e premissas institucionais é a compreensão de que o PIBID possibilita Valorização e

\begin{tabular}{l|c|c|c|c|c|c} 
() Rev. Educ. Perspec. & Viçosa, $M G$ & v.8 & n.3 & p.426-443 & set./dez. 2017 & eISSN 2178-8359 \\
\hline
\end{tabular}


qualificação do trabalho docente. $O$ que se evidencia nos objetivos institucionais classificados nesta categoria é que, de modo geral, as instituições compreendem que a vinculação ao programa deve estar alinhada à discussão mais ampla da formação e profissionalização docente.

Um outro eixo é a possibilidade de avanço na relação Universidade/escola e a interface na/da formação/atuação docente. Nesta categoria identificamos que os objetivos assumidos pelas instituições no desenvolvimento do programa dizem respeito à inserção e participação dos protagonistas no cotidiano escolar; a bidirecionalidade da relação universidade/escola na formação e atuação docente; o desenvolvimento de ações inovadoras e alternativas metodológicas; a otimização do processo de ensino e aprendizagem; o espaço de experiências metodológicas e as experiências pedagógicas como eixos transversais no processo de formação.

Com base na caracterização do programa, assim como as premissas metodológicas adotadas para o direcionamento de suas ações evidenciamos que um dos desafios lançados tem como base o modelo diferenciado de formação inicial e continuada de professores que o PIBID proporciona, mas que em nosso entendimento não pode se fortalecer como uma ação interna do programa, pois deve acima de tudo potencializar reflexões no interior dos diversos cursos de licenciaturas, a fim de que os mesmos também revejam seus desenhos curriculares e práticas formativas.

\section{REFERÊNCIAS}

ALARCÃO, Isabel; TAVARES, José. Supervisão da Prática Pedagógica: Uma perspectiva de desenvolvimento e aprendizagem. 2. ed. Coimbra: Almedina, 2013.

ALONSO, Maria Luiza Garcia; SILVA, Carlos. Questões críticas acerca da construção de um currículo formativo integrado. In: ALONSO, Luísa; ROLDÃO, Maria do Céu. Ser professor do $1^{\circ}$ Ciclo: Construindo a Profissão. Coimbra: Edições Almedina, 2005.

ARCE, Alessandra. Compre o kit neoliberal para a educação infantil e ganhe os dez passos para se tornar um professor reflexivo. Educação \& Sociedade, Campinas: SP, v. 22, n. 74, p. 251- 283, abril, 2001.

ARROIO, Agnaldo. "A Formação do Pós-Graduando em Química para a Docência em Nível Superior”. Revista Quim. Nova, v. 29, n. 6, p. 1387-1392, 2006.

BRASIL. CNE. Resolução CNE/CP 1/2002. Institui Diretrizes Curriculares Nacionais para a Formação de Professores da Educação Básica, em nível superior, curso de licenciatura, de

\begin{tabular}{l|c|c|c|c|c|c|} 
(C) Rev. Educ. Perspec. & Viçosa, $M G$ & v.8 & n.3 & p.426-443 & set./dez. 2017 & eISSN 2178-8359 \\
\hline
\end{tabular}


graduação plena. Diário Oficial da República Federativa do Brasil. Brasília, 09 de abril de 2002.

BRASIL. Decreto 7.219/2010. Dispõe sobre o Programa Institucional de Bolsa de Iniciação à Docência - PIBID e dá outras providências. Diário Oficial da República Federativa do Brasil. Brasília, 25 de junho de 2010.

CAPES. Portaria nº 096, de 18 de julho 2013. Regulamento do Programa Institucional de Bolsa de Iniciação à Docência (PIBID). Brasília: CAPES, 2013.

CUNHA, Maria Isabel. Profissionalização Docente: contradições e perspectivas. In: VEIGA, Ilma Passos de Sá; CUNHA, Maria Isabel (Org.). Desmistificando a profissionalização do Magistério. Campinas: Papirus, 1999.

DIEDRICH, Marlete Sandra; CAIMI, Flávia Eloisa; BRAGAGNOLO, Adriana. A Experiência de iniciação à docência no contexto das relações universidade-escola: a construção de uma história marcada pelo ato de dizer. EntreVer - Revista das Licenciaturas, Florianópolis, v. 3, n. 4, p. 262-277, jan./jun. 2013.

FELÍCIO, Helena Maria dos Santos. O PIBID como "terceiro espaço" de formação inicial de professores. Revista Diálogo Educacional, Curitiba, v. 14, n. 42, p. 415-434, maio/ago. 2014.

FELICIO, Helena Maria dos Santos, GOMES, Claudia; ALLAIN, Lucia Rezende. O PIBID na ótica dos licenciandos: possibilidades e limites no desenvolvimento do programa.

Educação. Santa Maria, v. 39, n. 2, p. 339-352, maio/ago. 2014.

FERNANDES, Maria José da Silva; MENDONÇA, Sueli Guadelupe de Lima. PIBID: uma contribuição à política de formação docente. EntreVer - Revista das Licenciaturas, v. 3, n. 4, p. 220-236, 2013.

FLORES, Maria Assunção. Currículo, Formação e Desenvolvimento Profissional. In: PACHECO, José Augusto (Org.). Política de integração curricular. Porto: Porto Editora, p. 147-165, 2000.

FORMOSINHO, Júlia. Formação de professores: aprendizagem profissional e acção docente. Porto: Porto Editora, 2009.

GATTI, Bernadete Angelina. Formação de Professores no Brasil: Características e problemas. Educação e Sociedade, Campinas, v. 31, n. 113, p. 1355-1379, out./dez. 2010.

GATTI, Bernadete Angelina; BARRETO, Elba Siqueira de Sá. Professores do Brasil: impasses e desafios. Brasília: UNESCO, 2009.

GOMES, Claudia; SANTOS, Geovania Lúcia dos; FELÍCIO, Helena Maria dos Santos. Da iniciação do PIBID à sua institucionalização na UNIFAL-MG: Desafios e perspectivas para

\begin{tabular}{l|c|c|c|c|c|c|} 
(C Rev. Educ. Perspec. & Viçosa, $M G$ & v.8 & n.3 & p.426-443 & set./dez. 2017 & eISSN 2178-8359 \\
\hline
\end{tabular}


uma política de formação e profissionalização docente. In: FELÍCIO, Helena Maria dos Santos et al. (Org.). Formação docente e prática pedagógica: Reflexões e vivências do PIBID/UNIFAL-MG. Alfenas, MG: Universidade Federal de Alfenas, p. 13-38, 2014.

GOMES, Claudia; FELÍCIO, Helena Maria dos Santos. Caminhos para a docência: o PIBID em foco. São Leopoldo: Oikos, 2012.

GOMES, Claudia; SOUZA, Vera Lucia Trevisan de. Psicologia e inclusão escolar: reflexões sobre o processo de subjetivação de professores. Psicologia: Ciência e Profissão, v. 32, p. 1, 2012.

GOMES, Claudia; BAZON, Fernanda Vilhena Mafra; LOZANO, Daniele. A formação de professores para a educação in/exclusiva. Revista Educação e Cultura Contemporânea (no prelo).

JARDILINI, José Rubens Lima.; OLIVERI, Andressa Maris Rezende. A formação continuada de professores no âmbito do PIBID na região dos inconfidentes-MG. EntreVer - Revista das Licenciaturas, v. 3, n. 4, p. 237-249, 2013.

NÓVOA, António. Os professores e a sua formação. 3. ed. Lisboa: Publicações Dom Quixote, 1997.

NÓVOA, António. Devolver a formação dos professores aos professores. Cadernos de Pesquisa em Educação, Vitória, ES, ano 9, v. 18, n. 35, p. 11-22, 2012.

OLIMPIO, Fernanda Mendes Paiva; GOMES, Claudia. Desafios e Perspectivas no Ensino de Química: uma análise a partir de pesquisas publicadas sobre a docência. Revista Labirinto, Porto Velho-RO, Ano XIV, v. 21, p. 358-382, 2014.

OLIVEIRA, Sandra Regina Ferreira de; LUGLE, Andreia Maria Cavaminami. O Pibid/Pedagogia da UEL: compondo a ação docente. EntreVer - Revista das Licenciaturas, v. 3, n. 4, p. 278-291, 2013.

OLIVEIRA, Leandra Martins de. "Políticas educacionais na formação da professora dos anos iniciais do ensino fundamental em cursos de licenciatura". Ensaio: Avaliação e Políticas Públicas em Educação., v. 18, n. 67, p. 235-252, 2010.

TARDIF, Maurice. Saberes docentes e formação profissional. 2. ed. Petrópolis, RJ: Vozes, 2002. 
NOTAS

${ }^{\text {i }}$ Embora o PIBID tenha sido criado pelo decreto 7219/2010, apresentou um edital de seleção em 2009.

ii O Coordenador Institucional é o professor de licenciatura que coordena o projeto PIBID na IES. O Coordenador de Gestão é o professor de licenciatura que auxilia o coordenador institucional na gestão do projeto na IES. O Coordenador de Área é o professor de licenciatura que coordena o subprojeto no interior do curso de licenciatura.

\section{Agradecimentos}

Agradecemos a FAPEMIG pelo apoio financeiro para a realização da pesquisa.

\section{Sobre as Autoras}

1Claudia Gomes - Professora Doutora do Instituto de Ciências Humanas e Letras da Universidade Federal de Alfenas (UNIFAL). E-mail: cg.unifal@gmail.com

${ }^{2}$ Helena Maria dos Santos Felício - Professora Doutora do Programa de Pós Graduação em Educação da Universidade Federal de Alfenas (UNIFAL). E-mail: hsfelicio@gmail.com 